Ken Oliphant

Richard W. Wright (eds.)

Medical Malpractice and Compensation

in Global Perspective

Tort and Insurance Law

TIL 32 


\title{
Tort and Insurance Law
}

\author{
Vol 32 \\ Edited by the \\ Institute for European Tort Law \\ of the Austrian Academy of Sciences \\ and the University of Graz \\ together with the \\ European Centre of Tort \\ and Insurance Law \\ and the Chicago-Kent Law Review
}

\section{De Gruyter}


Ken Oliphant

Richard W. Wright (eds.)

\title{
Medical Malpractice and Compensation in Global Perspective
}

\author{
With Contributions by
}

$\begin{aligned} \text { Kinga Bączyk-Rozwadowska } & \text { Bernhard A. Koch } \\ \text { Pieter Carstens } & \text { Robert B Leflar } \\ \text { Loutjie Coetzee } & \text { Ken Oliphant } \\ \text { Eduardo Dantas } & \text { Richard W. Wright } \\ \text { Claudia di Marzo } & \text { Mårten Schultz } \\ \text { Colleen M. Flood } & \text { Charles M. Silver } \\ \text { Richard Golderg } & \text { Marc S. Stauch } \\ \text { Florence G'Sell-Macrez } & \text { Bryan Thomas } \\ \text { Mette Hartlev } & \text { Stephan Todd } \\ \text { Genevieve Helleringer } & \text { Vibe Ulfbeck } \\ \text { David A. Hyman } & \text { Zhu Wang }\end{aligned}$




\author{
Institute for European Tort Law \\ Reichsratsstraße 17/2 \\ A-1010 Vienna \\ Tel.: +431427729651 \\ Fax: +43 1427729670 \\ E-Mail: etl@oeaw.ac.at \\ European Centre of Tort and Insurance Law \\ Reichsratsstraße 17/2 \\ A-1010 Vienna \\ Tel.: +431427729650 \\ Fax: +43 1427729670 \\ E-Mail: ectil@ectil.org \\ Chicago-Kent Law Review \\ Chicago-Kent College of Law \\ 565 West Adams Street \\ Chicago, Illinois 60661-3691 \\ Tel: 312-906-5190 \\ Fax: 312-906-5189 \\ E-Mail: cklawreview@kentlaw.iit.edu
}

ISBN 978-3-11-026997-0

e-ISBN 978-3-11-027023-5

ISSN 1616-8623

Bibliografische Information der Deutschen Nationalbibliothek

Die Deutsche Nationalbibliothek verzeichnet diese Publikation in der Deutschen Nationalbibliografie; detaillierte bibliografische Daten sind im Internet über http://dnb.d-nb.de abrufbar.

(C) 2013 Walter de Gruyter GmbH, Berlin/Boston

Druck: Hubert \& Co. GmbH \& Co. KG, Göttingen

Gedruckt auf säurefreiem Papier

Printed in Germany

www.degruyter.de 